\title{
Role of Direct Antiviral Agents in Treatment of Chronic Hepatitis C Infection in Renal Transplant Recipients
}

\author{
Sourabh Sharma $\mathbb{D}^{D}$, Debabrata Mukherjee, Ranjith K. Nair, Bhaskar Datt, and Ananth Rao
}

Army Hospital Research \& Referral, Delhi, India

Correspondence should be addressed to Sourabh Sharma; drsourabh05@gmail.com

Received 18 December 2017; Accepted 27 February 2018; Published 28 March 2018

Academic Editor: Simon C. Robson

Copyright (c) 2018 Sourabh Sharma et al. This is an open access article distributed under the Creative Commons Attribution License, which permits unrestricted use, distribution, and reproduction in any medium, provided the original work is properly cited.

\begin{abstract}
Background. Since the introduction of direct antiviral agents (DAAs), morbidity of HCV has considerably decreased but still no guidelines have been formulated in renal transplant recipients (RTRs). We studied efficacy and tolerability of direct antiviral agents in RTRs. Methods. This prospective observational study was conducted at Army Hospital Research \& Referral, Delhi, from June 2016 to May 2017. Forty-five HCV infected RTRs with stable graft function were included. Results. Median time between renal transplantation and the start of anti-HCV therapy was 36 months (1-120 months). The majority (66.7\%) were infected with genotype 3. Baseline median HCV RNA level was $542648 \mathrm{IU} / \mathrm{ml}$ (1189-55028534 IU/ml). Sofosbuvir-Ribavirin combination (24 weeks) was given to 30 patients including 3 cirrhotics, Ledipasvir-Sofosbuvir combination to 8 patients, and DaclatasvirSofosbuvir combination to 7 patients, including 2 cirrhotics. Rapid virological response was observed in 29 patients treated with Sofosbuvir/Ribavirin, all 8 patients on Sofosbuvir/Ledipasvir, and all 7 patients on Sofosbuvir/Daclatasvir. End treatment response and sustained virological response (12 weeks) were achieved in all patients irrespective of genotype or treatment regimen. Decrease in mean HCV RNA level and transaminase level was statistically significant $(p<0.01)$. Ribavirin was significantly associated with anaemia $(p=0.032)$. Conclusions. DAA regimens are well tolerated and highly efficacious. Response to DAA is good irrespective of genotype, drug combination, initial HCV RNA level, age or sex of patient, or graft age. However, Sofosbuvir/Ledipasvir and Sofosbuvir/Daclatasvir combination is preferable.
\end{abstract}

\section{Introduction}

Chronic hepatitis $\mathrm{C}$ virus (HCV) infection remains an important health problem, which is associated with deleterious consequences in renal transplant recipients [1-4]. Besides hepatic complications, several extrahepatic complications contribute to reduced patient and allograft survival in HCV infected renal transplant recipients (RTRs) [5-9]. HCV infection is associated with an increased risk of mortality in these patients as a consequence of liver disease, higher infection rates, and cardiovascular disease $[1,6,9]$. Moreover, HCV infection in RTR is an independent risk factor for graft loss, and it is associated with proteinuria, chronic rejection, transplant glomerulopathy, posttransplant diabetes, and HCV associated glomerulonephritis [7, 9-11].

However, HCV infection should not be considered as a contraindication for renal transplantation because patient survival is better with transplantation than on dialysis. Until recently, treatment of HCV infection was IFN $\alpha$ based [12], which had been associated with higher renal allograft rejection rates $[13,14]$ and very modest success in viral eradication $[12,15]$. Therefore, IFN $\alpha$ therapy is preferable before transplantation and is presently recommended only in rapid worsening hepatic injury, like in Fibrosing cholestatic hepatitis $[16,17]$ or in life-threatening vasculitis $[16]$ when potential benefits outweigh risks in cases of life-threatening liver injury [18]. IFN-free treatment regimens, like direct antiviral agents (DAAs), because of their greater efficacy, reduced toxicity, and minimal interaction with immunesuppressants currently represent promising and attractive therapeutic options. The efficacy of these oral agents used with Ribavirin or in combination with one another yields a sustained virological response at 12 weeks of greater than $90 \%$ among patients who are treatment naïve [19]. However, the 
majority of initial clinical trials for the DAAs have excluded RTR or patients with chronic kidney disease with eGFR less than $30 \mathrm{ml} / \mathrm{min}$, including those on hemodialysis. Though the efficacy of DAAs in liver-transplant recipients had been established in studies done by Forns et al. [20] and Charlton et al. [21] in 2015, published data on safety and efficacy of DAAs in RTR is scarce. Clinical trials are required to closely evaluate these regimens in RTRs. There is also a need for further studies to determine optimal immunosuppressive regimens after transplantation in $\mathrm{HCV}$ infected recipients.

\section{Materials and Methods}

2.1. Setting. This study was conducted from June 2015 to May 2017 at Department of Nephrology, Army Hospital Research \& Referral, New Delhi.

2.2. Study Design. This is a single-center prospective observational study. Renal transplant recipients at least one month after transplant with replicating HCV infection and fulfilling the inclusion criteria were enrolled after informed written consent. The study was approved by institutional ethical committee and institutional scientific committee.

2.3. Sample Size. In this study, DAA therapy was assumed to be effective with SVR $24>90 \%$ in HCV infected RTR [22] compared to interferon based regimen in which SVR 24 used to be achieved in $50 \%$ of the cases [12]

$$
\begin{aligned}
& p 1=0.5 ; \\
& p 2=0.9 .
\end{aligned}
$$

Effect size, that is, difference between proportions $(p 1-$ $p 2),=0.5-0.9=-0.4$.

$$
\text { Pooled prevalence }=\frac{p 1+p 2}{2}=0.7 .
$$

So,

$$
\text { sample size }=\frac{2(1.96+0.84)^{2} 0.4(1-0.4)}{(-0.4)^{2}}=24 .
$$

It was planned to include at least thirty patients in the study. However, finally forty-five patients were recruited for the study.

\subsection{Inclusion Criteria}

(i) Renal transplant recipient $\geq 18$ years of age, at least 1 month after transplant surgery

(ii) Stable graft function with eGFR $\geq 30 \mathrm{~mL} / \mathrm{min} / 1.73 \mathrm{~m}^{2}$ as estimated by MDRD study equation

(iii) Replicating HCV infection (detectable HCV RNA by quantitative PCR)

(iv) Absolute neutrophil count $\geq 750$ cells $/ \mathrm{mm}^{3}$; platelet count $\geq 50,000$ cells $/ \mathrm{mm}^{3}$; hemoglobin $\geq 11 \mathrm{~g} / \mathrm{dL}$ for women and $\geq 12 \mathrm{~g} / \mathrm{dL}$ for men

\subsection{Exclusion Criteria}

(i) Patients $<18$ years of age

(ii) Pregnant or nursing women

(iii) Coexisting malignancy

(iv) Coinfection with Human Immunodeficiency Virus or Hepatitis B Virus

(v) eGFR $<30 \mathrm{~mL} / \mathrm{min} / 1.73 \mathrm{~m}^{2}$ as estimated by MDRD study equation

2.6. Conduct of Study. At the initial visit, after informed written consent, all patients were subjected to a baseline hemogram, renal function tests (blood urea nitrogen and serum creatinine level), and liver function tests (serum AST and ALT levels). eGFR was calculated by MDRD study equation. Baseline CNI (Tacrolimus/Cyclosporine) levels were assessed by LC-MS/MS method. Pretreatment quantitative HCV RNA level was determined by HCV RT-PCR kit v1.0 (RealStar ${ }^{\circledR}$, Altona Diagnostics $\mathrm{GmbH}$ ). The concentration of Quantification Standards was given in IU per ml, corresponding to the concentration of purified nucleic acid. HCV genotype was determined using VERSANT HCV LiPA 2.0. Liver fibrosis was evaluated before therapy by measuring liver stiffness, using a Fibroscan according to the manufacturer's instructions (Fibroscan 402, Echosens, Paris, France). The results of elastometry were expressed in kilopascals, and the median value was considered representative of the elastic modulus of the liver. A liver stiffness of less than $7.4 \mathrm{kPa}$ was considered to be equivalent to a METAVIR score of F0 to F2, a liver stiffness of 7.5-12.4 $\mathrm{kPa}$ was considered to be equivalent to a METAVIR score of F3, and cirrhosis (METAVIR F4) was defined by values of $12.5 \mathrm{kPa}$ or greater [23].

All patients were treated with DAA therapy. Initially, only Sofosbuvir/Ribavirin combination was available in Indian market, so initially (2015) HCV genotype 1 infected patients were given Sofosbuvir $400 \mathrm{mg}$ daily/weight based Ribavirin, adjusted for anaemia $(n=7)$. Subsequently, once Ledipasvir $90 \mathrm{mg} / \mathrm{Sofosbuvir} 400 \mathrm{mg}$ and Daclatasvir $60 \mathrm{mg} / \mathrm{Sofosbuvir}$ $400 \mathrm{mg}$ daily regimen became available (2016 onwards), newer regimen was given according to genotype. The types of DAA combinations and the duration of therapies according to each genotype are presented in Table 1.

Initial Ribavirin dose was weight based; patients $<60 \mathrm{Kg}$ weight received $800 \mathrm{mg}$ daily, patients between 60 and $74 \mathrm{Kg}$ weight received $1000 \mathrm{mg}$ daily, and patients with weight $\geq$ $75 \mathrm{Kg}$ received $1200 \mathrm{mg}$ daily dose. The dose was modified as per hemoglobin levels as follows: $\mathrm{Hb}<10 \mathrm{gm} / \mathrm{dl}: 400 \mathrm{mg}$ daily if weight $<60 \mathrm{Kg}$ or $600 \mathrm{mg}$ daily if weight $\geq 60 \mathrm{Kg}, \mathrm{Hb}<$ $8.5 \mathrm{gm} / \mathrm{dl}$ : Ribavirin discontinued and reintroduced once $\mathrm{Hb}$ $>8.5 \mathrm{gm} \%$.

In all patients, hemogram, kidney function tests, transaminase levels, and virological parameters were assessed before therapy, at 4 weeks, 12 weeks, and 24 weeks during the therapy, and at 12 weeks after completion of therapy. Adherence to the treatment was determined by pill counts at each visit and patient interviews. 
TABLE 1: Combination of DAAs and treatment according to genotype and DAA availability.

\begin{tabular}{lccr}
\hline HCV genotype & $N$ & DAA combination & Duration (weeks) \\
\hline 1 & 7 & Sofosbuvir + Ribavirin & 24 \\
& 8 & Ledipasvir + Sofosbuvir & 12 \\
3 & 23 & Sofosbuvir + Ribavirin & 24 \\
& 7 & Daclatasvir + Sofosbuvir & $12(24$ in cirrhotic; $n=2)$ \\
\hline
\end{tabular}

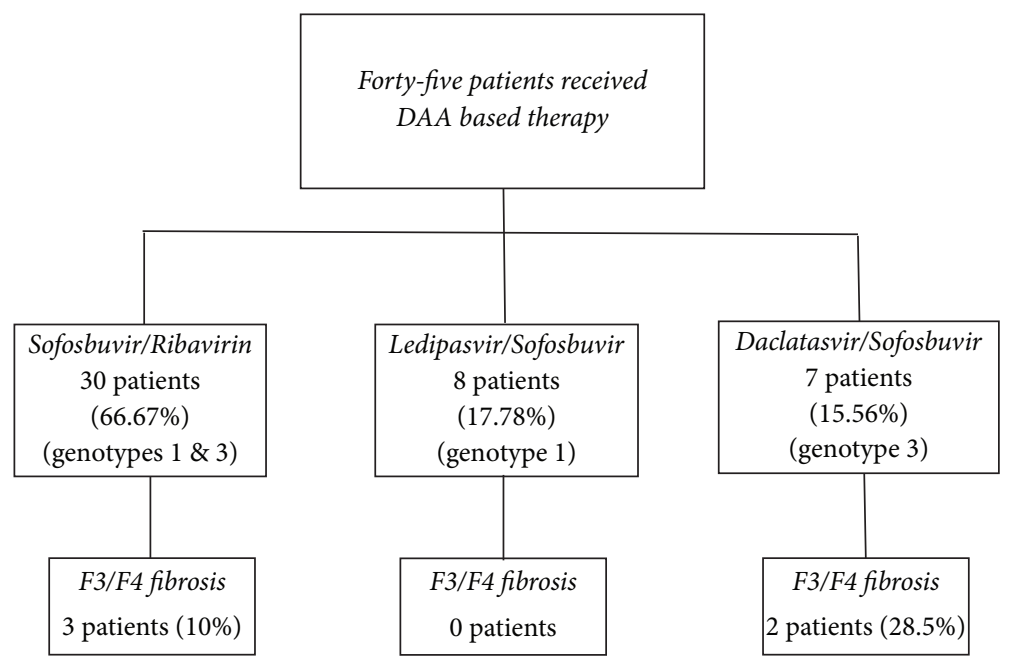

FIGURE 1: Study population: DAA regimen stratification of study population.

2.7. Outcomes. The primary efficacy end point was fall in HCV RNA level to less than $25 \mathrm{IU} / \mathrm{mL}$ at week 12 or 24 of therapy (end of treatment response, ETR) while the secondary efficacy end point was achievement of SVR12 (sustained virological response after 12 weeks of completion of therapy) $[28,29]$.

Rapid virological response (RVR) is defined as undetectable HCV RNA using a sensitive PCR assay at week 4 of therapy, and early virological response (EVR) is defined as undetectable HCV RNA at week 12 of therapy [28, 29].

The safety end points included the rate of adverse events and rate of discontinuation of DAA therapy in the HCV infected RTRs.

2.8. Statistical Evaluation. The data so collected were entered in MS Excel. Results are expressed as mean \pm standard deviation and median. Comparison of continuous and categorical variables was done by student $t$-test and chi-square test, respectively. The level of significance was defined as $p<0.05$. SPSS ${ }^{\circledR}$ (Statistical Package for the Social Sciences) version 22 Statistics for Windows (IBM ${ }^{\circledR}$ Corp, Armonk, NY) was used for data analysis.

\section{Results}

3.1. Baseline Patient Characteristics. Forty-five RTRs were included in the study and received DAA therapy. Baseline patient demographic and clinical characteristics are depicted in Table 2.
3.2. HCV Genotype and Viral Load at Baseline. HCV genotype and viral load at baseline are shown in Table 2.

3.3. DAA Regimens. All patients were treated with DAA therapy. DAA regimen given to the study population is as depicted in Figure 1. Advanced fibrosis stage (F3) was seen in $2(4.4 \%)$ patients and cirrhosis (F4) was present at baseline in $5(11.1 \%)$. Thirty-eight (84.4\%) RTRs had equivalent METAVIR score of F0 to F2. Out of the five patients with cirrhosis, none had hepatic decompensation.

3.4. Patients with Cirrhosis. There were five patients with compensated cirrhosis and all of them were old transplant patients. One patient, infected with genotype 1, was treated with Sofosbuvir/Ribavirin for 24 weeks. Out of the remaining four cirrhotic cases with genotype 3 infection, two were treated with Sofosbuvir/Ribavirin for 24 weeks and two with Daclatasvir/Sofosbuvir regimen for 24 weeks.

3.5. Virological Response. Response of the patients to DAA therapy is depicted in Table 3.

(a) Rapid virological response (RVR): RVR was observed in 29 of the 30 patients treated with Sofosbuvir/Ribavirin. All 8 patients on Sofosbuvir/Ledipasvir and all 7 patients on Sofosbuvir/Daclatasvir showed RVR.

(b) Early virological response (EVR): EVR was observed in 29 of the 30 patients (96.67\%) treated with Sofosbuvir/Ribavirin. One patient (HCV genotype 3) failed to 
TABLE 2: Demographic and clinical characteristics at baseline.

\begin{tabular}{|c|c|}
\hline Characteristics & Overall subjects $(n=45)$ \\
\hline Recipient age (years), median (range) & $38(23-68)$ \\
\hline \multicolumn{2}{|l|}{ Gender, $n(\%)$} \\
\hline Male & $23(51.1 \%)$ \\
\hline Female & $22(48.9 \%)$ \\
\hline Time to initiation of therapy after transplantation (months), median (range) & $36(1-120)$ \\
\hline \multicolumn{2}{|l|}{ Patients detected $\mathrm{HCV}$ positive, $n(\%)$} \\
\hline Before transplantation & $18(40 \%)$ \\
\hline After transplantation & $27(60 \%)$ \\
\hline Diabetes mellitus, $n(\%)$ & $4(8.9 \%)$ \\
\hline New onset diabetes after transplantation, $n(\%)$ & $8(17.8 \%)$ \\
\hline \multicolumn{2}{|l|}{ HCV genotype, $n(\%)$} \\
\hline 1 & $15 / 45(33.3 \%)$ \\
\hline 3 & $30 / 45(66.7 \%)$ \\
\hline $2,4,6$ & Nil \\
\hline \multicolumn{2}{|l|}{ METAVIR fibrosis stage, $n(\%)$} \\
\hline F0-F2 & $38(84.4 \%)$ \\
\hline F3-F4 & $7(15.6 \%)$ \\
\hline Hepatic decompensation & Nil \\
\hline HCV viral load (IU/ml), median (range) & $542648(1189-55028534)$ \\
\hline Serum creatinine at treatment initiation $(\mathrm{mg} / \mathrm{dl})$, median (range) & $1.22(0.66-2.0)$ \\
\hline Estimated GFR $\left(\mathrm{ml} / \mathrm{min} / 1.73 \mathrm{~m}^{2}\right)$, median (range) & $57(30-118)$ \\
\hline \multicolumn{2}{|l|}{$\begin{array}{l}\text { Baseline immunosuppression regimen (in combination with Mycophenolate } \\
\text { Mofetil/Azathioprine and Prednisolone), } n(\%)\end{array}$} \\
\hline Tacrolimus based & $39(86.7 \%)$ \\
\hline Cyclosporine based & $4(8.9 \%)$ \\
\hline Everolimus based & $2(4.4 \%)$ \\
\hline
\end{tabular}

TABLE 3: Virological response to DAA therapy.

\begin{tabular}{lcccc}
\hline Virological response & Sofosbuvir/Ribavirin $(n=30)$ & Sofosbuvir/Daclatasvir $(n=7)$ & Sofosbuvir/Ledipasvir $(n=8)$ & Total $(n=45)$ \\
\hline RVR & 29 & 7 & 8 & 44 \\
ETR & 29 & 7 & 8 & 44 \\
SVR12 & 29 & 7 & 8 & 44 \\
\hline
\end{tabular}

achieve EVR but there was substantial decline in HCV RNA level from $1020062 \mathrm{IU} / \mathrm{ml}$ to $460 \mathrm{IU} / \mathrm{ml}$ after 12 weeks of therapy.

(c) End treatment response (ETR): one of the patients included in this study, who was on Sofosbuvir/Ribavirin, expired during study due to Nocardiosis, after achieving EVR. End of treatment response (ETR) was achieved in all 29 remaining patients treated with Sofosbuvir/Ribavirin including one who had not achieved EVR. All 8 patients with Sofosbuvir/ Ledipasvir and 7 patients with Sofosbuvir/Daclatasvir achieved ETR. Hence, all patients achieved ETR irrespective of the genotype or treatment regimen used.

(d) Sustained virological response at 12 weeks (SVR 12): overall, all patients included in the study (excluding one expired) achieved SVR 12 irrespective of genotype or treatment regimen. No patient experienced relapse during therapy.

The kinetics of HCV viral load clearance have been depicted in Figure 2.

3.6. Liver Function. Serum AST/ALT levels decreased significantly $(p<0.0001)$ following DAA therapy (Figure 3 ).

3.7. Renal Allograft Function. At the initiation of antiviral therapy, all patients had a GFR of $30 \mathrm{ml} / \mathrm{min}$ or greater. Twenty-one patients (46.67\%) had a GFR of $60 \mathrm{ml} / \mathrm{min}$ or greater, 12 patients $(26.67 \%)$ had a GFR between 45 and $59 \mathrm{ml} / \mathrm{min}$, and 12 patients $(26.67 \%)$ had a GFR between 30 and $44 \mathrm{ml} / \mathrm{min}$. During therapy, overall no significant change in graft function was observed. 


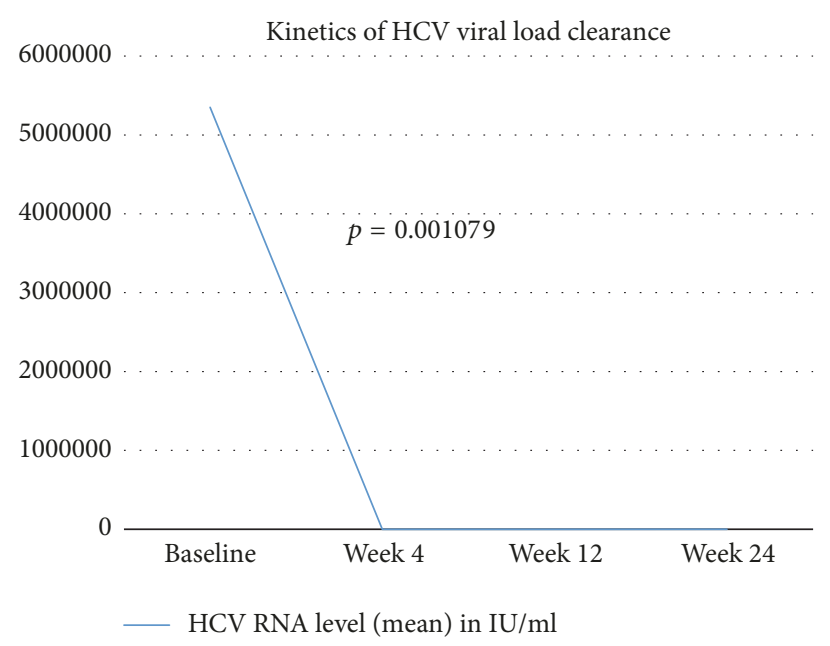

FIGURE 2: Kinetics of HCV viral load clearance. The decrease in mean HCV RNA level from baseline at start of therapy to that at week 4 was statistically significant (two-sample $t$-test; $p=0.001079$ ).

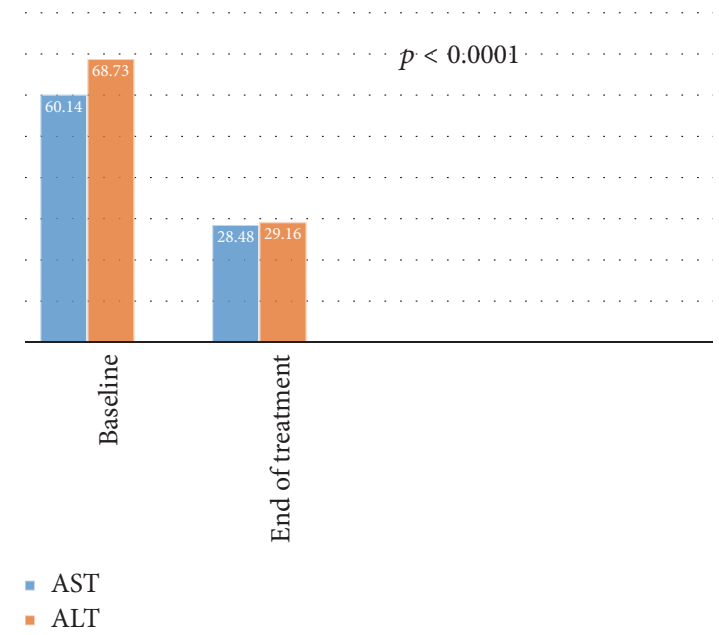

FIGURE 3: Outcome of serum transaminase level before and after DAA therapy (two-sample $t$-test; $p<0.0001$ ).

Two (4.44\%) patients experienced an increase in serum creatinine $>25 \%$ during treatment. Out of these two, one patient had developed diarrhoea and as it improved, the graft function recovered spontaneously. The other patient underwent graft biopsy showing an antibody mediated rejection, which was treated with plasmapheresis, IVIg, and Bortezomib. His graft function improved but did not touch the baseline. Tacrolimus level of first patient was $5.8 \mathrm{ng} / \mathrm{ml}$ (4 years after transplant) while that of second patient was $9.8 \mathrm{ng} / \mathrm{ml}$ (1 month after transplant), which were well within therapeutic range.

3.8. Adverse Events. The Sofosbuvir/Daclatasvir and Sofosbuvir/Ledipasvir regimen were well tolerated with least reported adverse events. Adverse events are shown in Table 4.

3.9. Hematological Tolerance. As depicted in Table 5, Ribavirin was significantly associated with anaemia $(p=0.032)$.
Ribavirin dose reduction was required in nine patients (81.82\%), out of which two patients (18.18\%) required discontinuation of Ribavirin. Recombinant erythropoietin support or blood transfusion was not required in any patient. No patient discontinued therapy due to adverse events related to DAA therapy.

3.10. Immunosuppression. All of the forty-five patients were on triple drug immunosuppression. Thirty-nine patients (86.67\%) were on Tacrolimus based immunosuppressive regimen and four $(8.89 \%)$ were on Cyclosporine based regimen while two (4.44\%) were on Everolimus based regimen. The most common combination therapy was Tacrolimus, Mycophenolate Mofetil, and Prednisolone. All patients had stable CNI (Tacrolimus/Cyclosporine) trough levels during DAA therapy. No change in immunosuppression was made during DAA therapy or within 12 weeks of completion of therapy. 
TABLE 4: Adverse events reported while on DAA therapy.

\begin{tabular}{lcccc}
\hline Adverse events & Sofosbuvir/Ribavirin $(n=30)$ & Sofosbuvir/Daclatasvir $(n=7)$ & Sofosbuvir/Ledipasvir $(n=8)$ & Total $(n=45)$ \\
\hline Anaemia & 11 & 1 & 0 & 1 \\
Diarrhoea & 9 & 2 & 3 & 12 \\
Headache & 6 & 1 & 2 & 12 \\
Nausea & 4 & 4 & 0 & 10 \\
Leucopenia & 3 & 0 & 0 & 3 \\
Thrombocytopenia & 3 & 0 & 0 & 2 \\
Influenza-like illness & 2 & 1 & 1 & 2 \\
Myalgia & 1 & 0 & & 2 \\
Graft dysfunction & 1 & &
\end{tabular}

TABle 5: Hematological tolerance. Association of anemia with Ribavirin.

\begin{tabular}{lccc}
\hline & Patients on DAA with Ribavirin & Patients on DAA without Ribavirin & $p$ value (chi-square test) \\
\hline Anaemia & 11 & 1 & 0.03193 (chi-square statistic 4.6023) \\
Ribavirin dose reduction & 9 & 0 & 0 \\
Ribavirin discontinuation & 2 & 0 & \\
EPO/transfusion & 0 & 0 & \\
\hline
\end{tabular}

\section{Discussion}

$\mathrm{HCV}$ infection remains an important health problem in the hemodialysis and renal transplant population and is associated with deleterious consequences. Until recently, treatment of $\mathrm{HCV}$ infection was IFN $\alpha$ based, which has been associated with poor efficacy, poor compliance due to adverse effects, and higher renal allograft rejection rates. DAAs represent promising and attractive therapeutic options because of their greater efficacy, reduced toxicity, and minimal interaction with immunosuppressants. However, data in RTRs is scarce and yet there is no approved therapy or guideline for use of DAA in this population. At the time study was initiated (June 2015), there were no published data on use of DAAs in RTRs. Four studies were published on this subject over the last two years [24-27]. Our aim was to study the efficacy of DAA in HCV positive RTRs in achieving ETR and SVR. In this singlecenter prospective observational study, conducted between Jun 2015 and May 2017, we describe our center's experience in treating $\mathrm{HCV}$ infected RTR with DAA regimen.

Forty-five patients received DAA therapy in our study and this sample size is highest among prospective single-center studies published so far. The study pattern and demographics of different published studies have been compared with our study in Table 6.

The study population in our center was younger as compared to other studies which can be explained by fact that the majority of the patients treated for ESRD at this center are younger, serving Armed Forces personnel or their family member. Forty-nine percent of patients in our study were women unlike other studies where the majority of patients were men.

The median time between renal transplantation and start of anti-HCV therapy was shorter as compared to other studies. Nine HCV infected patients were started on DAA therapy after one month of transplantation once graft function stabilized. This is the reason for shorter median transplant-to-treatment time in our study.

Forty percent of patients (18/45) had documented HCV infection prior to transplantation, while 27 patients were detected to have $\mathrm{HCV}$ infection after undergoing renal transplantation. Lin et al. [26] have described $88 \%$ of the patients being documented to have $\mathrm{HCV}$ infection prior to transplantation. In our study, the majority of patients were diagnosed with HCV infection after transplantation, possibly because, at our center, HCV RNA PCR is not done routinely prior to transplantation; pretransplant HCV screening is based upon presence of anti-HCV antibodies in serum which can be negative in early infection. Also, detection of anti$\mathrm{HCV}$ antibodies by third-generation enzyme-immunoassay allows false negative results in dialysis patients [30, 31].

In this study, median serum creatinine at HCV treatment initiation was $1.22 \mathrm{mg} / \mathrm{dl}$ and the median eGFR was $57 \mathrm{~mL} / \mathrm{min} / 1.73 \mathrm{~m}^{2}$. These values are comparable to that described by Lin et al. [26] in their study (median baseline serum creatinine $1.21 \mathrm{mg} / \mathrm{dl}$ and mean baseline eGFR $70.9 \mathrm{ml} / \mathrm{min} / 1.73 \mathrm{~m}^{2}$ ) but lower than that reported by Fernández et al. [27] who had included patients with eGFR < $30 \mathrm{ml} / \mathrm{min} / 1.73 \mathrm{~m}^{2}$ in their study.

Genotype 3 was the most prevalent genotype in our patient population followed by genotype 1 . As depicted in Table 6, in other studies done in USA, France, and Spain, genotype 1 was the predominant $\mathrm{HCV}$ infection in RTRs. This is in concordance with studies which show that HCV genotype 3 is most prevalent in India while genotype 1 is more prevalent in Europe and Americas [32,33].

In our study, rapid virological response (RVR) was observed in $97.78 \%$. One patient had expired during study due to Nocardiosis, after achieving EVR. End treatment response (ETR) and SVR 12 were 100\% among the remaining 44 patients and none of them experienced relapse. We did not observe any difference in rate of SVR12 in patients receiving 
TABLE 6: Comparison of study pattern, demographics, virological profile, and response to therapy with other published studies.

\begin{tabular}{|c|c|c|c|c|c|}
\hline & Kamar et al. [24] & $\begin{array}{c}\text { Sawinski et al. } \\
\text { [25] }\end{array}$ & Lin et al. [26] & Fernández et al. [27] & Present study \\
\hline Study period & 2014-2015 & 2014-2015 & 2013-2015 & $2015-2016$ & 2015-2017 \\
\hline Study design & Prospective & Prospective & Retrospective & Retrospective & Prospective \\
\hline Study center & Single-center & Single-center & Multicenter & Multicenter, national & Single-center \\
\hline Place of study & France & USA & USA & Spain & India \\
\hline Sample size & 25 & 20 & 24 & 103 & 45 \\
\hline Age in years & $54 \pm 10$ & $57 \pm 5.5$ & $60(34-70)$ & $55(27-74)$ & $38(23-68)$ \\
\hline $\mathrm{M}: \mathrm{F}$ & $15: 10$ & $16: 4$ & $19: 5$ & $69: 34$ & $23: 22$ \\
\hline $\begin{array}{l}\text { Time since renal } \\
\text { transplantation }\end{array}$ & $\begin{array}{l}146 \text { months } \\
(1-329)\end{array}$ & $\begin{array}{l}888 \text { days } \\
(341-1621)\end{array}$ & 96 months $(2-492)$ & 147 months (1-561) & 36 months (1-120) \\
\hline \multicolumn{6}{|l|}{ Genotype: } \\
\hline 1 & 19 & 17 & 21 & 85 & 15 \\
\hline 3 & 1 & 0 & 0 & 7 & 30 \\
\hline $2,4,6$ & 5 & 3 & 3 & 10 & 0 \\
\hline HCV RNA level & $\begin{array}{l}\text { Mean } 6.33 \pm \\
0.6 \log \mathrm{IU} / \mathrm{ml}\end{array}$ & $\begin{array}{c}\text { Median } \\
6.5 \log \mathrm{IU} / \mathrm{ml} \\
(\text { range } \\
6.3-7 \log \mathrm{IU} / \mathrm{ml})\end{array}$ & $\begin{array}{c}\text { Median 1,922,552 IU/ml } \\
(1060-22,600,000 \mathrm{IU} / \mathrm{ml})\end{array}$ & $\begin{array}{l}\text { Median } 6.61 \log \mathrm{IU} / \mathrm{ml} \\
(2.87-7.79 \log \mathrm{IU} / \mathrm{ml})\end{array}$ & $\begin{array}{c}\text { Median } 5,42,648 \mathrm{IU} / \mathrm{ml} \\
\quad(\text { range }\end{array}$ \\
\hline \multicolumn{6}{|l|}{ Virological response: } \\
\hline RVR & $88 \%(22 / 25)$ & - & - & $59 \%$ & $97.78 \%$ \\
\hline ETR & $100 \%$ & $95 \%$ & $83.33 \%$ & $100 \%$ & $97.78 \%$ \\
\hline SVR 12 & $100 \%$ & $100 \%$ & $91 \%$ & $98 \%$ & $100 \%$ \\
\hline \multicolumn{6}{|l|}{ Immunosuppression: } \\
\hline Tacrolimus based & $19(76 \%)$ & $19(95 \%)$ & $19(79.16 \%)$ & $75(72.82 \%)$ & $39(86.67 \%)$ \\
\hline Cyclosporine based & $5(20 \%)$ & $1(5 \%)$ & $3(12.5 \%)$ & $12(11.65 \%)$ & $4(8.89 \%)$ \\
\hline mTOR inhibitor based & $1(4 \%)$ & 0 & $1(4.16 \%)$ & $7(6.8 \%)$ & $2(4.44 \%)$ \\
\hline
\end{tabular}

12 weeks of therapy without Ribavirin or 24 weeks of therapy with Ribavirin. We observed that DAA is highly effective in patients with cirrhosis, though all patients with cirrhosis were treated with DAA therapy for 24 weeks.

As depicted in Table 6, in the studies of Kamar et al. [24] and Sawinski et al. [25], SVR 12 was noted in $100 \%$ of the cases while Ladino et al. [11] and Fernández et al. [27] achieved SVR 12 in $91 \%$ and $98 \%$ of the cases, respectively. We observed that there was no impact on response by HCV genotype, initial HCV RNA level, age or sex of the patient, or age of the graft. Also, there is no difference in response to therapy on the basis of timing of DAA initiation; those treated within the first 6 months after transplantation cleared the virus as easily as those treated later after transplantation.

Serum AST/ALT levels normalized after DAA therapy $(p<0.0001)$ in our study. Kamar et al. [24] had also shown a significant decline in transaminase levels in their study. Similarly, Sawinski et al. [25] and Lin et al. [26] have also shown a declining trend in their respective studies.

Overall, DAA therapy was well tolerated with no significant impact on graft function. Two patients experienced an increase in serum creatinine $>25 \%$ during treatment. Out of these two, one patient recovered spontaneously while the other patient underwent graft biopsy which showed an antibody mediated rejection. Lin et al. [26] and Fernández et al. [27] have also reported rejection while on DAA therapy for which Kamar et al. [24] and Lin et al. [26] have postulated that this might be related to increased hepatic metabolism of CNI as a consequence of improvement in liver function following viral eradication. Kamar et al. [24] and Lin et al. [26] had reported no significant change in graft function during DAA therapy. No rejection or graft loss was observed in their study. Sawinski et al. [25] also had similar results but have reported rise in serum creatinine by $>0.25 \mathrm{mg} / \mathrm{dL}$ in four patients. This rise was attributed to supratherapeutic Tacrolimus levels in two patients. Fernández et al. [27] did not find any significant change in serum creatinine or eGFR in their study but reported increase in serum creatinine $>25 \%$ in seventeen $(16 \%)$ patients.

We observed that there was no incidence of discontinuation of DAA therapy because of significant adverse effect. Ribavirin was significantly associated with anaemia (chi-square test; $p=0.032$ ). This observation is supported by the study done by Fernández et al. [27] in which they have reported association between Ribavirin use and anaemia. Fourteen out of 42 cases on Ribavirin (33\%) developed anaemia requiring dose adjustment in 13 (31\%) and discontinuation in 8 (19\%) cases. Six cases $(14 \%)$ received a blood transfusion. Sawinski 
et al. [25] have also reported good tolerability to DAA therapy in their study. In their study, two out of three patients treated with Ribavirin (66.67\%) required dose reduction due to anaemia, one of whom required a blood transfusion. Lin et al. [26] reported 11 patients (46\%) to have adverse events during DAA therapy. One patient developed serious adverse event while on Sofosbuvir/Simeprevir in form of sinus bradycardia and junctional escape rhythm. Patients on Ribavirin experienced more adverse events as compared to those not on Ribavirin. Two out of seven patients on Ribavirin had to discontinue Ribavirin because of shortness of breath, fatigue, and gout flare while two patients (28.57\%) developed anaemia which recovered after treatment.

We observed that all patients in our study had stable CNI trough levels during DAA therapy. No change in immunesuppression was made during DAA therapy or within 12 weeks of completion of therapy. This finding is supported by study done by Lin et al. [26] in which majority of patients had stable CNI trough levels during DAA therapy. Kamar et al. [24] also reported no significant change in dose during DAA therapy. However, after HCV clearance, there was decrease in Tacrolimus trough levels, whereas Tacrolimus dose remained unchanged. Sawinski et al. [25] reported that almost half $(45 \%)$ of the patients required dose adjustment of their CNI during therapy though this was not significantly associated with a particular regimen $(p=0.84)$. Similarly, in a study done by Fernández et al. [27], Tacrolimus dose adjustment was required in 47 out of 75 patients (62.6\%). This was not significantly associated with a particular regimen of DAAs ( $p>0.05)$. Recently, Fernández-Ruiz et al. [34] reported that $80.6 \%$ of the cases on Tacrolimus required dose adjustment while on DAA therapy to maintain desired levels. In their study, graft function remained stable while on therapy but significant decrease in graft function was observed ( $p$ value $<0.001)$ throughout the first 12 months after the end of therapy. This study highlights the role of continuous monitoring of drug levels even after completion of DAA regimen.

There were certain limitations in our study. Our follow-up period in the patients inducted later into the study was necessarily shorter than that for patients included in the earlier part of study, though all patients were followed up for 12 weeks after completion of therapy. The number of patients treated with Ledipasvir/Sofosbuvir and Daclatasvir/Sofosbuvir was lower than those put on Sofosbuvir/Ribavirin due to recent availability of these drugs in India. Since HCV RNA PCR is not done routinely during pretransplant evaluation at our center, $60 \%$ of patients were detected to have HCV infection only in posttransplant period.

\section{Conclusions}

We conclude by our study that all-oral, interferon-free DAA regimens are well tolerated and are highly efficacious, with an SVR12 rate of $100 \%$ among a heterogeneous and complex renal transplant population with $\mathrm{HCV}$ infection. Response to DAA was good irrespective of genotype, drug combination, initial HCV RNA level, age or sex of the patient, or age of the graft. However, Sofosbuvir/Ledipasvir and Sofosbuvir/Daclatasvir combination is the preferred drug combination in genotype 1 and genotype 3, respectively, as they were tolerated better compared to DAA with Ribavirin.

There is no difference in response to therapy on the basis of timing of DAA initiation. Patients who were treated within the first 6 months after transplantation cleared the virus as easily as those treated later after transplantation. DAA is highly effective in patients with cirrhosis when treated for 24 weeks. Hence, HCV positive ESRD patients with compensated cirrhosis should not be denied transplant.

The high efficacy and tolerability of DAA hold great promise for renal transplant population in improving their outcome. Chronic HCV infected patients awaiting renal transplantation can be safely transplanted and then initiated on DAAs once their eGFR rises above $30 \mathrm{~mL} / \mathrm{min} / 1.73 \mathrm{~m}^{2}$.

$\begin{array}{ll}\text { Abbreviations } \\ \text { ALT: } & \text { Alanine aminotransferase } \\ \text { AST: } & \text { Aspartate aminotransferase } \\ \text { BUN: } & \text { Blood urea nitrogen } \\ \text { CNI: } & \text { Calcineurin inhibitor } \\ \text { DAA: } & \text { Direct antiviral agents } \\ \text { eGFR: } & \text { Estimated glomerular filtration rate } \\ \text { ESRD: } & \text { End stage renal disease } \\ \text { ETR: } & \text { End of treatment response } \\ \text { EVR: } & \text { End virological response } \\ \text { GFR: } & \text { Glomerular filtration rate } \\ \text { Hb: } & \text { Hemoglobin } \\ \text { HCV: } & \text { Hepatitis C virus } \\ \text { IFN: } & \text { Interferon } \\ \text { IFN }: & \text { Interferon alpha } \\ \text { IU: } & \text { International unit } \\ \text { LC-MS/MS: } & \text { Liquid chromatography-mass } \\ & \text { spectrometry } \\ \text { MDRD: } & \text { Modification of diet in renal disease } \\ \text { MMF: } & \text { Mycophenolate Mofetil } \\ \text { PCR: } & \text { Polymerase chain reaction } \\ \text { RNA: } & \text { Ribonucleic acid } \\ \text { RTR: } & \text { Renal transplant recipients } \\ \text { RVR: } & \text { Rapid virological response } \\ \text { SVR12: } & \text { Sustained virological response at } 12 \text { weeks } \\ & \text { (of completion of treatment) } \\ \text { SVR24: } & \text { Sustained virological response at 24 weeks } \\ \text { TLC: } & \text { Total leucocyte count. } \\ & \end{array}$

\section{Conflicts of Interest}

The authors declare that no conflicts of interest exist.

\section{Authors' Contributions}

Sourabh Sharma designed and performed the study, collected and analysed the data, and wrote the paper. Debabrata Mukherjee performed the study and analysed the data. Ranjith K. Nair, Bhaskar Datt, and Ananth Rao performed the study. 


\section{References}

[1] J. M. Morales and F. Fabrizi, "Hepatitis C and its impact on renal transplantation," Nature Reviews Nephrology, vol. 11, no. 3, pp. 172-182, 2015.

[2] R. Carpio, G. E. Pamugas, R. Danguilan, and E. Que, "Outcomes of Renal Allograft Recipients with Hepatitis C," Transplantation Proceedings, vol. 48, no. 3, pp. 836-839, 2016.

[3] Z. Rostami, M. H. Nourbala, S. M. Alavian, F. Bieraghdar, Y. Jahani, and B. Einollahi, "The impact of hepatitis $C$ virus infection on kidney transplantation outcomes: A systematic review of 18 observational studies," Hepatitis Monthly, vol. 11, no. 4, pp. 247-254, 2011.

[4] F. Fabrizi, P. Martin, V. Dixit, and P. Messa, "Meta-analysis of observational studies: Hepatitis $\mathrm{C}$ and survival after renal transplant," Journal of Viral Hepatitis, vol. 21, no. 5, pp. 314-324, 2014.

[5] R. D. Bloom and J. R. Lake, "Emerging issues in hepatitis C virus-positive liver and kidney transplant recipients," American Journal of Transplantation, vol. 6, no. 10, pp. 2232-2237, 2006.

[6] M. Gürsoy, N. Güvener, R. Köksal et al., "Impact of HCV infection on development of posttransplantation diabetes mellitus in renal allograft recipients," Transplantation Proceedings, vol. 32, no. 3, pp. 561-562, 2000.

[7] J. M. Morales, B. Domínguez-Gil, D. Sanz-Guajardo, J. Fernández, and F. Escuin, "The influence of hepatitis B and hepatitis $\mathrm{C}$ virus infection in the recipient on late renal allograft failure," Nephrology Dialysis Transplantation, vol. 19, no. 3, pp. iii72-iii76, 2004.

[8] J. M. Cruzado, M. Carrera, J. Torras, and J. M. Grinyó, "Hepatitis $\mathrm{C}$ virus infection and de novo glomerular lesions in renal allografts," American Journal of Transplantation, vol. 1, no. 2, pp. 171-178, 2001.

[9] B. A. Bouthot, B. V. R. Murthy, C. H. Schmid, A. S. Levey, and B. J. G. Pereira, "Long-term follow-up of hepatitis $\mathrm{C}$ virus infection among organ transplant recipients: Implications for policies on organ procurement," Transplantation, vol. 63, no. 6, pp. 849853, 1997.

[10] F. Fabrizi, S. Verdesca, P. Messa, and P. Martin, "Hepatitis C Virus Infection Increases the Risk of Developing Chronic Kidney Disease: A Systematic Review and Meta-Analysis," Digestive Diseases and Sciences, vol. 60, no. 12, pp. 3801-3813, 2015.

[11] M. Ladino, F. Pedraza, and D. Roth, "Hepatitis c virus infection in chronic kidney disease," Journal of the American Society of Nephrology, vol. 27, no. 8, pp. 2238-2246, 2016.

[12] S. J. Hadziyannis, H. Sette Jr., T. R. Morgan et al., "eginterferon$\alpha 2 \mathrm{a}$ and ribavirin combination therapy in chronic hepatitis $\mathrm{C}$ : a randomized study of treatment duration and ribavirin dose," Annals of Internal Medicine, vol. 140, no. 5, pp. 346-I67, 2004.

[13] R. K. Sharma, S. B. Bansal, A. Gupta, S. Gulati, A. Kumar, and N. Prasad, "Chronic hepatitis $\mathrm{C}$ virus infection in renal transplant: Treatment and outcome," Clinical Transplantation, vol. 20, no. 6, pp. 677-683, 2006.

[14] S. Baid, N. Tolkoff-Rubin, S. Saidman et al., "Acute humoral rejection in hepatitis $\mathrm{C}$-infected renal transplant recipients receiving antiviral therapy," American Journal of Transplantation, vol. 3, no. 1, pp. 74-78, 2003.

[15] F. Fabrizi, A. Penatti, P. Messa, and P. Martin, "Treatment of hepatitis $\mathrm{C}$ after kidney transplant: A pooled analysis of observational studies," Journal of Medical Virology, vol. 86, no. 6, pp. 933-940, 2014.
[16] Kidney Disease: Improving Global Outcomes (KDIGO) CKD Work Group, "KDIGO 2012 clinical practice guideline for the evaluation and management of chronic kidney disease," Kidney International Supplements, vol. 7, pp. 1-59, 2017.

[17] M. G. Ghany, D. B. Strader, D. L. Thomas, and L. B. Seeff, "Diagnosis, management, and treatment of hepatitis C: an update," Hepatology, vol. 49, no. 4, pp. 1335-1374, 2009.

[18] Kidney Disease: Improving Global Outcomes (KDIGO) CKD Work Group, "Guideline 4: Management of HCV-infected patients before and after kidney transplantation," Kidney International, vol. 73, pp. S53-S68, 2008.

[19] J.-M. Pawlotsky, "New hepatitis C virus (HCV) drugs and the hope for a cure: Concepts in anti-HCV drug development," Seminars in Liver Disease, vol. 34, no. 1, pp. 22-29, 2014.

[20] X. Forns, M. Charlton, J. Denning et al., "Sofosbuvir compassionate use program for patients with severe recurrent hepatitis C after liver transplantation," Hepatology, vol. 61, no. 5, pp. 14851494, 2015.

[21] M. R. Charlton, D. Samuel, M. P. Manns et al., "226 Ledipasvir/Sofosbuvir With Ribavirin Is Safe in >600 Decompensated and Post Liver Transplantation Patients With HCV Infection: An Integrated Safety Analysis of the Solar 1 and Solar 2 Trials," Gastroenterology, vol. 148, no. 4, p. S-971, 2015.

[22] M. P. Manns, M. Buti, E. Gane et al., "Hepatitis C virus infection," Nature Reviews Disease Primers, vol. 3, p. 17006, 2017.

[23] N. Ganne-Carrié, M. Ziol, V. De Ledinghen et al., "Accuracy of liver stiffness measurement for the diagnosis of cirrhosis in patients with chronic liver diseases," Hepatology, vol. 44, no. 6, pp. 1511-1517, 2006.

[24] N. Kamar, O. Marion, L. Rostaing et al., "Efficacy and Safety of Sofosbuvir-Based Antiviral Therapy to Treat Hepatitis C Virus Infection after Kidney Transplantation," American Journal of Transplantation, vol. 16, no. 5, pp. 1474-1479, 2016.

[25] D. Sawinski, N. Kaur, A. Ajeti et al., "Successful Treatment of Hepatitis C in Renal Transplant Recipients with Direct-Acting Antiviral Agents," American Journal of Transplantation, vol. 16, no. 5, pp. 1588-1595, 2016.

[26] M. V. Lin, M. E. Sise, M. Pavlakis et al., "Efficacy and safety of direct acting antivirals in kidney transplant recipients with chronic hepatitis C virus infection," PLoS ONE, vol. 11, no. 7, Article ID e0158431, 2016.

[27] I. Fernández, R. Muñoz-Gómez, J. M. Pascasio et al., "Efficacy and tolerability of interferon-free antiviral therapy in kidney transplant recipients with chronic hepatitis C," Journal of Hepatology, vol. 66, no. 4, pp. 718-723, 2017.

[28] European Association for the Study of the Liver, "EASL Recommendations on Treatment of Hepatitis C 2016," Journal of Hepatology, vol. 66, no. 1, pp. 153-194, 2017, http://www.easl.eu/ medias/cpg/HCV2016/Summary.pdf.

[29] AASLD-IDSA, "Recommendations for testing, managing, and treating hepatitis C," in HCV Guidelines, 2017, http://www .hcvguidelines.org.

[30] G. N. Dalekos, D. S. Boumba, K. Katopodis et al., "Absence of $\mathrm{HCV}$ viraemia in anti-HCV-negative haemodialysis patients," Nephrology Dialysis Transplantation, vol. 13, no. 7, pp. 18041806, 1998.

[31] P. M. Schneeberger, I. Keur, W. van der Vliet et al., "Hepatitis $\mathrm{C}$ virus infections in dialysis centers in The Netherlands: A national survey by serological and molecular methods," Journal of Clinical Microbiology, vol. 36, no. 6, pp. 1711-1715, 1998. 
[32] V. Saraswat, S. Norris, and R. J. de Kneqt, "Historical epidemiology of hepatitis C virus (HCV) in select countries," Journal of Viral Hepatitis, vol. 22, pp. 6-25, 2015.

[33] S. Attaullah, S. Khan, and I. Ali, "Hepatitis C virus genotypes in Pakistan: a systemic review," Virology Journal, vol. 8, article 433, 2011.

[34] M. Fernández-Ruiz, N. Polanco, A. García-Santiago et al., "Impact of anti-HCV direct antiviral agents on graft function and immunosuppressive drug levels in kidney transplant recipients: a call to attention in the mid-term follow-up in a singlecenter cohort study," Transplant International, 2018. 


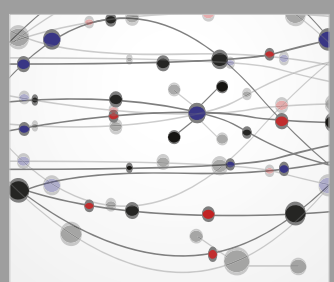

The Scientific World Journal
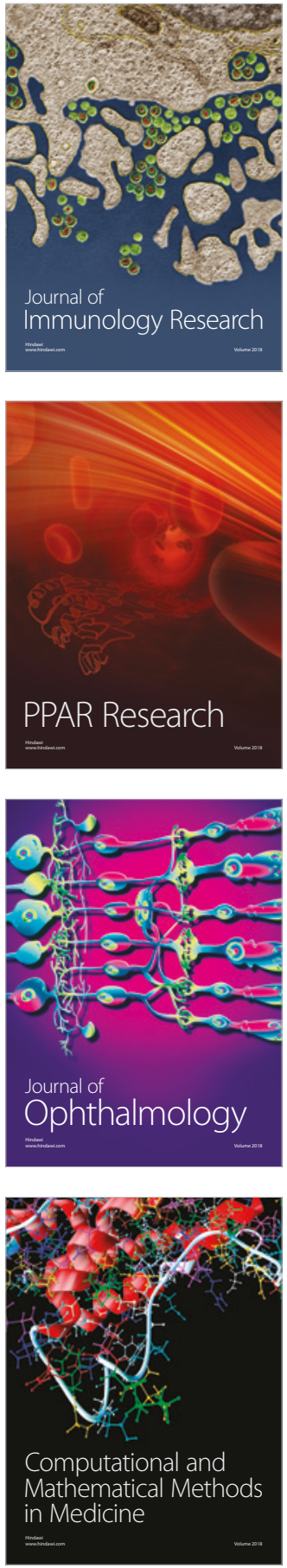

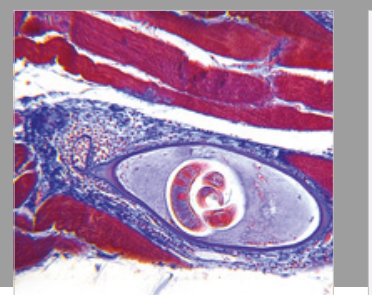

Gastroenterology Research and Practice

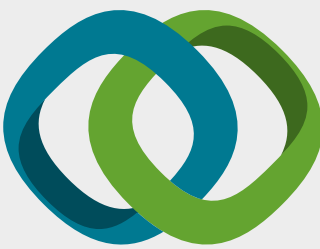

\section{Hindawi}

Submit your manuscripts at

www.hindawi.com
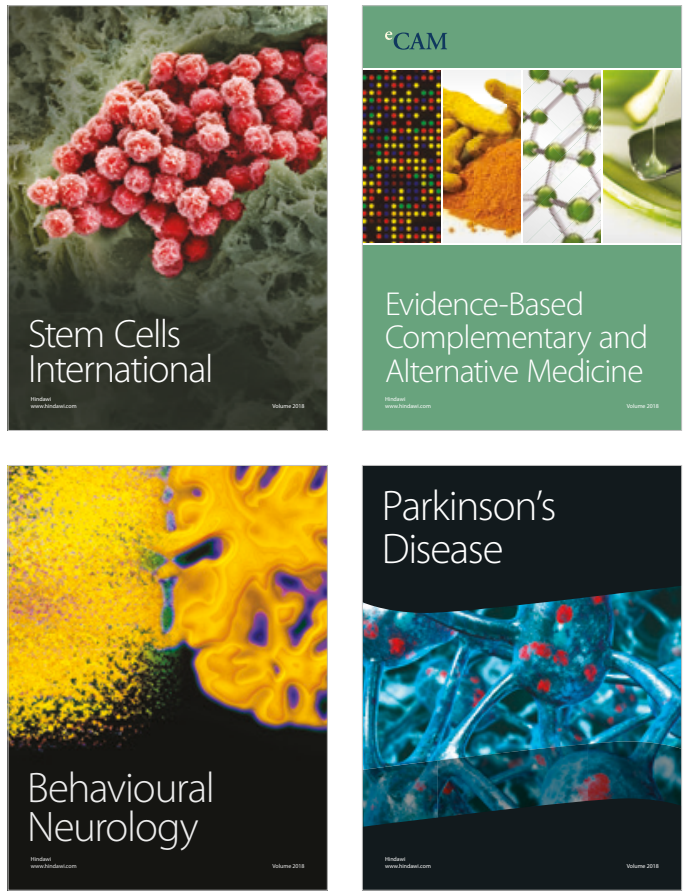

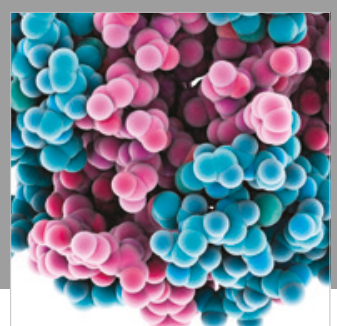

ournal of

Diabetes Research

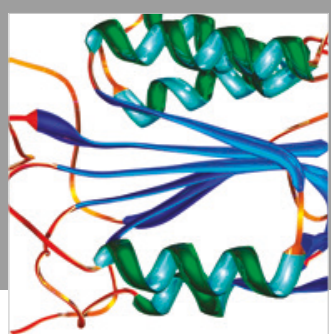

Disease Markers
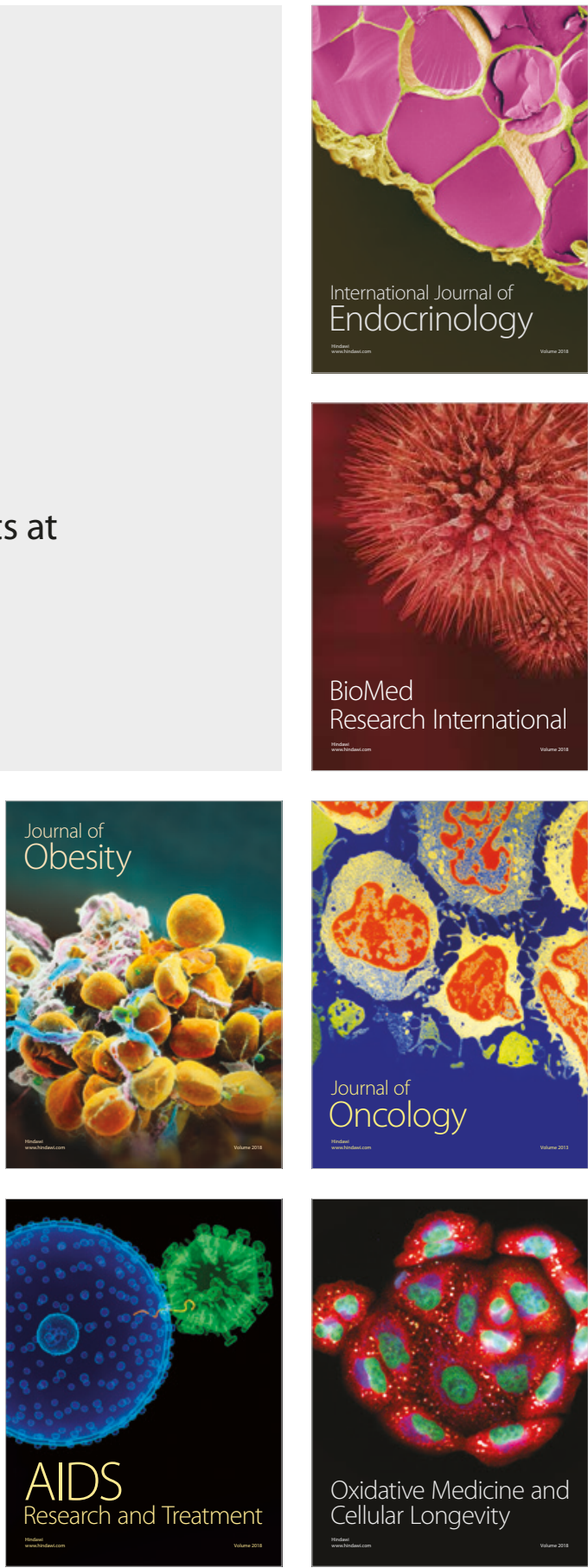